\title{
Theoretical and Experimental Emittance Measurements for a Thin Liquid Sheet Flow
}

Amy N. Englehart

Cleveland State University

Cleveland, Ohio

Marc W. McConley

Massachusetts Institute of Technology

Cambridge, Massachusetts

Donald L. Chubb

Lewis Research Center

Cleveland, Ohio

Prepared for the

34th AIAA Aerospace Sciences Meeting sponsored by the American Institute of Aeronautics and Astronautics Reno, Nevada, January 15-18, 1996

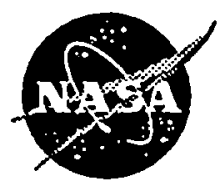

National Aeronautics and

Space Administration

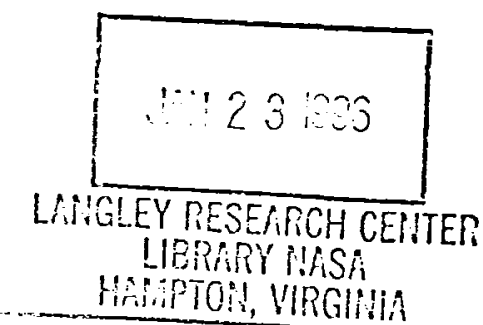


Trade names or manufacturers' names are used in this report for identification only. This usage does not constitute an official endorsement, either expressed or implied, by the National Aeronautics and Space Administration. 


\title{
THEORETICAL AND EXPERIMENTAL EMITTANCE MEASUREMENTS FOR A THIN LIQUID SHEET FLOW
}

\author{
Amy N. Englehart \\ Cleveland State University \\ Cleveland, Ohio 44115 \\ Marc W. McConley \\ Massachusetts Institute of Technology \\ Cambridge, Massachusetts 02139 \\ Donald L. Chubb \\ National Aeronautics and Space Administration \\ Lewis Research Center \\ Cleveland, Ohio 44135
}

\begin{abstract}
$\underline{\text { Abstract }}$
Thin liquid sheet flows are excellent candidates for use in space radiator systems. Surface tension forces at the edges of a thin liquid $(-200 \mu \mathrm{m})$ sheet flow result in a triangularly shaped sheet. Such a geometry is ideal for an external flow radiator. Since the fluid must have very low vapor pressure, Dow Corning 705 silicone oil was used and the emittance of a flowing sheet of oil was determined by two methods. The emittance was derived as a function of the temperature drop between the top of the sheet and the coalescence point of the sheet, the sink temperature, the volumetric flow and the length of the sheet. The emittance for the oil was also calculated using an extinction coefficient determined from spectral transmittance data of the oil. The oil's emittance ranges were high, ranging from 0.67 to 0.87 depending on the sheet thickness and sheet temperature. The emittance derived from the temperature drop was slightly less than the emittance calculated from transmittance data.
\end{abstract}

\section{Introduction}

The liquid sheet radiator (LSR) is an external flow radiator similar in several ways to other external flow radiators such as the liquid droplet (LDR) ${ }^{1}$ and liquid belt radiators. ${ }^{2}$ All of these radiator concepts potentially have lower mass than solid wall radiators such as pumped loop and heat pipe radiators. They are also nearly immune to micrometeoroid penetration. However, the LSR has the added advantage of simplicity. Surface tension causes a thin (100 to $300 \mu \mathrm{m})$ liquid sheet to coalesce to a point (Fig. 1). As a result, the sheet flow has a triangular shape. Such a triangular sheet is desirable since it allows collection of the flow at a single point. To obtain a similar triangular area for the LDR requires very accu- rate aiming of many $\left(10^{5}\right.$ to $\left.10^{6}\right)$ droplet streams. Simplicity of the LSR should also result in lower mass for the LSR compared to the LDR and liquid belt radiators.

A major problem for all external flow radiators is the requirement that the working fluid be of very low $\left(\sim 10^{8}\right.$ torr) vapor pressure in order to keep evaporative losses low. As a result, working fluids are limited to certain oils (such as used in diffusion pumps) for low temperatures (300 to $400 \mathrm{~K}$ ) and liquid metals for higher temperatures.

Previous research on the LSR has been directed at understanding the fluid mechanics of thin sheet flows $\mathrm{s}^{3,5}$ and assessing the stability of such flows, especially with regard to the formation of holes in the sheet. ${ }^{6}$ The latest topic investigated was the emittance of thin sheet flows. The emittance was calculated from spectral transmittance data for the Dow Corning 705 silicone oil. The emittance was also derived as a function of measurable quantities, namely, the temperature drop between the top of the sheet and the temperature at the coalescence point of the sheet, the sink temperature, the volumetric flow rate and the length of the sheet. Since the temperature drop was on the order of a few tenths of a degree, very accurate measurement was needed. In addition, because the temperature drop was so small, temperature fluctuations within the oil were a potential problem and this was investigated.

\section{Analysis}

\section{Theoretical Sheet Emittance from Transmittance Data}

The following expression is given for the spectral emittance, $\varepsilon_{\lambda}$ of an infinite sheet, ${ }^{3}$

$$
\varepsilon_{\lambda}=1-\tau_{\lambda}=1-2 \mathrm{E}_{3}\left(\alpha_{\lambda} \tau\right)
$$


where $\tau_{\lambda}$ is the spectral transmittance, $\alpha_{\lambda}$ is the extinction coefficient, $\tau$ is the thickness of the sheet and $E_{3}(x)$ is the exponential integral.

$$
E_{3}(x)=\int_{0}^{1} u e^{(-x / u)} d u
$$

The total hemispherical emittance is defined as follows, ${ }^{4}$

$$
\varepsilon=\frac{\int_{0}^{\infty} \varepsilon_{\lambda} e_{\lambda_{b}}(\lambda, T) d \lambda}{\sigma_{s b} T^{4}}
$$

where $e_{\lambda b}$ is the black body hemispherical spectral emissive power, ${ }^{4} \mathrm{~T}$ is the temperature, $\lambda$ is the wavelength, and $\sigma_{\mathrm{sb}}$ is the Stefan-Boltzmann constant $\left(5.67 \times 10^{-8} \mathrm{~W} /\right.$ $\mathrm{m}^{2} \mathrm{~K}^{4}$ ).

The black body hemispherical emissive power is expressed as,

$$
e_{\lambda_{b}}=\frac{2 \pi C_{1}}{\lambda^{5}\left(e^{C_{2} / \lambda T}-1\right)}
$$

Here $\mathrm{C}_{1}=\mathrm{hc}_{\mathrm{o}}^{2}=0.59544 \times 10^{8} \mathrm{~W} \mu \mathrm{m}^{4} / \mathrm{m}^{2}$ and $\mathrm{C}_{2}=\mathrm{hc}_{\mathrm{o}}$ $\mathrm{k}=14388 \mu \mathrm{m} \mathrm{K}$; where $\mathrm{h}$ is Planck's constant, $\mathrm{c}_{\mathrm{o}}$ is the speed of light and $\mathrm{k}$ is the Boltzmann constant.

From the measured spectral transmission, $\tau_{\lambda}$, the extinction coefficient, $\alpha_{\lambda}$, is calculated using Eq. (1). The hemisperical emittance, $\varepsilon_{\lambda}$, is then calculated for any thickness, $\tau$, and any temperature, $T$, using Eqs. (1) to (3).

\section{Experimental Sheet Emittance}

The flow of the liquid sheet radiator is depicted graphically in Fig. 1. The working fluid flows with velocity, $w_{0}$, from a slit of prescribed width, $W$, and thickness, $\tau$, at one end of the device $(z=0)$ to form a triangular sheet of liquid.

The planform area of the sheet acts as a radiating surface. When surrounded by a sink temperature, $T_{\infty}$, lower than the initial fluid temperature, the fluid temperature decreases as a function of the vertical position, $z$, until reaching the coalescence point. The power radiated from the sheet is given by the following,

$$
P_{\mathrm{rad}}=2 \sigma_{\mathrm{sb}} \int_{\mathrm{A}} \varepsilon\left(\mathrm{T}^{4}-\mathrm{T}_{\infty}^{4}\right) \mathrm{dA}
$$

where $\mathrm{T}$ is the temperature of the sheet, $\mathrm{A}$ is the sheet area and $\varepsilon$ is the total hemispherical emittance. The factor of two arises because both sides of the sheet radiate. The background in the experiment is a black painted surface and it is assumed to behave as a black body $\left(\varepsilon_{\infty}=1\right)$.

Before proceeding, a number of simplifying assumptions can be made. The Froude number (the ratio of the kinetic energy to gravitational potential energy) for this experiment is high enough that gravitational effects on the sheet geometry can be neglected. In that case, the sheet shape is exactly triangular. ${ }^{5}$ If heat transfer due to conduction or convection is neglected (this is reasonable provided a sufficient vacuum is maintained), then in the steady state, the radiated power must balance the enthalpy change,

$$
P_{\mathrm{rad}}=\rho Q C_{\mathrm{p}}\left(\mathrm{T}_{1}-\mathrm{T}_{2}\right)
$$

Here $\rho$ is the density of the fluid, $C_{p}$ is the specific heat, and $Q$ is the volumetric flow rate. If it is assumed that the emittance is a constant for the sheet and that $T$ varies only in the z-direction then Eqs. (5) and (6) yield the following:

$\Delta \mathrm{T}=\mathrm{T}_{1}-\mathrm{T}_{2}=\frac{2 \sigma_{\mathrm{sb}} \varepsilon \mathrm{W}}{\rho \mathrm{QC}} \int_{0}^{\mathrm{L}}\left(\mathrm{T}^{4}-\mathrm{T}_{\infty}^{4}\right)\left(1-\frac{\mathrm{z}}{\mathrm{L}}\right) \mathrm{dz}$

Integration of Eq. (7) requires knowing $\mathrm{T}(\mathrm{z})$, which is found by solving the energy equation. Assuming that temperature gradients exist only in the flow direction yields the following for the steady state energy equation:

$$
\frac{\rho Q C_{p d T}}{W d z}=-2 \sigma_{s b} \varepsilon\left(T^{4}-T_{\infty}^{4}\right)
$$

By defining the following dimensionless parameters:

$$
h=\frac{\sigma_{s b} \varepsilon W L T_{1}^{3}}{\rho Q C_{p}}
$$

and

$$
\overline{\mathrm{z}}=\frac{\mathrm{z}}{\mathrm{L}}
$$

Eqs. (7) and (8) can now be rewritten as follows,

$$
\begin{gathered}
\frac{\Delta \mathrm{T}}{\mathrm{h}_{1}}=2 \int_{0}^{1}\left[\left(\frac{\mathrm{T}}{\mathrm{T}_{1}}\right)^{4}-\left(\frac{\mathrm{T}_{\infty}}{\mathrm{T}_{1}}\right)^{4}\right][1-\overline{\mathrm{z}}] \mathrm{d} \overline{\mathrm{z}} \\
\frac{\mathrm{dT}}{\mathrm{T}^{4}-\mathrm{T}_{\infty}^{4}}=-2 \mathrm{~h} \mathrm{~T}_{1}^{-3} \mathrm{~d} \overline{\mathrm{z}}
\end{gathered}
$$


For $0 \leq T_{\infty} \leq T_{1}$, the solution to Eq. (12) subject to the initial condition $T=T_{1}$ at $z=0$ is given by:

$$
\begin{aligned}
4 h\left(\frac{T_{\infty}}{T_{1}}\right)^{3} \bar{z}= & \tan ^{-1} \frac{T / T_{1}}{T_{\infty} / T_{1}}-\tan ^{-1} \frac{1}{T_{\infty} / T_{1}}-\frac{1}{2} \\
& \times \ln \left[\frac{\left(T / T_{1}-T_{\infty} / T_{1}\right)\left(1+T_{\infty} / T_{1}\right)}{\left(T / T_{1}+T_{\infty} / T_{1}\right)\left(1-T_{\infty} / T_{1}\right)}\right]
\end{aligned}
$$

Equation (13), which gives $T / T_{1}$ as a function $\bar{z}$, is used to carry out the integration in Eq. (11).

The solution for the temperature drop, $\Delta \mathrm{T}$, can be solved in the limit of low background temperature $\left(\mathrm{T}_{\infty} \rightarrow 0\right)$. The method outlined in Appendix B was used to solve Eq. (11) for $\Delta \mathrm{T}$ in the limit of low background temperature $\left(T_{\infty} \rightarrow 0\right)$. This result is given by Eq. (B-4):

$$
\lim _{\mathrm{T}_{\infty} \rightarrow 0} \frac{\Delta \mathrm{T}}{\mathrm{hT}_{1}}=\frac{4 \mathrm{~h}+1-(6 \mathrm{~h}+1)^{2 / 3}}{4 \mathrm{~h}^{2}}
$$

The range of $h$ appropriate for test conditions is $0.0004<h<0.004$. For these very small values of $h$, Eq. (B-4) is found to be,

$$
\lim _{\mathrm{T}_{\infty} \rightarrow 0} \frac{\Delta \mathrm{T}}{\mathrm{hT}_{1}}=\frac{4 \mathrm{~h}+1-(6 \mathrm{~h}+1)^{2 / 3}}{4 \mathrm{~h}^{2}} \approx 1
$$

Thus, $\Delta \mathrm{T} \approx \mathrm{hT}_{1}$ which is the same solution obtained from Eq. (11) if $T \approx T_{1}$ and $T_{\infty} \rightarrow 0$. Therefore, in the case $T_{\infty} \rightarrow 0$, it is a good approximation to assume $T \approx$ $\mathrm{T}_{1}$ in the integration of Eq. (11). The relative error in this constant temperature approximation was found numerically in Appendix B to be proportional to h,

$$
\begin{aligned}
\lim _{T_{\infty} \rightarrow 0} \frac{(\Delta T)_{\text {approx }}-(\Delta T)_{\text {exact }}}{(\Delta T)_{\text {approx }}} \\
\quad=\frac{4 h^{2}-4 h-1+(6 h+1)^{2 / 3}}{4 h^{2}}=\frac{8}{3} h
\end{aligned}
$$

In experimental conditions, $T_{\infty}$ is not likely to approach zero, it may be closer to $T_{1}$. An analysis of $T_{\infty} \rightarrow T_{1}$ is given in Appendix B. It was found that the constant temperature approximation is still valid. The limit on the error in making the approximation was $\leq 8 \mathrm{~h} / 3$. Since $h$ encountered in the experiments is 0.004 to 0.0004 , the constant temperature approximation is valid. Figure 2 compares the exact solution (obtained by a numerical solution of Eqs. (11) and (13) using Newton's method) with the constant temperature approximation, Eq. (14), at a worst case value of $h=0.004$, corresponding approximately to $T_{1}=400 \mathrm{~K}, \mathrm{~W}=23.5 \mathrm{~cm}$ and $\tau=100 \mu \mathrm{m}$. This represents the highest value of $h$ that is encountered in the experiments. As Fig. 2 shows there is excellent agreement between the exact and approximate solutions.

The percent deviation between the exact and approximate solutions has an upper bound given by Eq. (B-14):

$$
\frac{(\Delta T)_{\text {approx }}-(\Delta T)_{\text {exact }}}{(\Delta T)_{\text {approx }}} \leq \frac{8}{3} h
$$

For the condition $h=0.004$ considered in Fig. 2 , the deviation is approximately 1 percent. Thus, the constanttemperature approximation is sufficiently accurate when calculating the temperature drop.

If a measurement for $\Delta \mathrm{T}$ is available then the emittance can be solved for by a straight-forward integration of Eq. (8) for constant $T=T_{1}$ :

$$
\frac{\Delta \mathrm{T}}{\mathrm{hT}} \approx 1-\left(\frac{\mathrm{T}_{\infty}}{\mathrm{T}_{1}}\right)^{4} \Rightarrow \varepsilon=\frac{\rho \mathrm{C}_{\mathrm{p}} \mathrm{Q} \Delta \mathrm{T}}{\sigma_{\mathrm{SB}} \mathrm{WL}\left(\mathrm{T}_{1}^{4}-\mathrm{T}_{\infty}^{4}\right)}
$$

The emittance is calculated directly from eq. (14) provided measurements are available for the three temperatures $T_{1}, T_{2}$, and $T_{\infty}$; the flow rate, $Q$; and the sheet length, $L$. The specific heat, $C_{p}$, and the density, $\rho$, are known as functions of temperature.

\section{$\underline{\text { Results }}$}

Theoretical Sheet Emittance from Transmittance Data

Transmittance data was taken for a sample of the Dow Corning 705 silicone oil used in the emittance measurement. The measuring device was an FTIR spectrophotometer. The spectrophotometer measures the overall transmission of the oil plus the transmission of the windows containing the oil (Fig. 3). Therefore the potassium bromide $(\mathrm{KBr})$ window transmittance and reflectance must be taken into account in determining the extinction coefficient.

The oil transmittance is shown as a function of wavelength in Fig. 4 and the window's transmittance is shown as a functions of wavenumbers in Fig. 5. From this data, the extinction coefficient was calculated according to Eq. (A-25). It is shown in appendix A that the extinction coefficient needed for the spectral emittance can be expressed as, 


$$
\alpha_{\lambda}=\frac{-\ln \left\{\frac{-b \pm \sqrt{b^{2}-4 a c}}{2 a}\right\}}{d}
$$

where,

$$
\begin{gathered}
\mathrm{a}=\mathrm{T}_{\lambda}\left(\mathrm{r}_{\mathrm{mw}}+\mathrm{r}_{\mathrm{aw}} \tau_{\mathrm{w}}^{2}\left[1-2 \mathrm{r}_{\mathrm{mw}}\right]\right)^{2} \\
\mathrm{~b}=\tau_{\mathrm{w}}^{2}\left(1-\mathrm{r}_{\mathrm{aw}}\right)^{2}\left(1-\mathrm{r}_{\mathrm{mw}}\right)^{2} \\
\mathrm{c}=-\mathrm{T}_{\lambda}\left(1-\mathrm{r}_{\mathrm{aw}} \mathrm{r}_{\mathrm{mw}} \tau_{\mathrm{w}}^{2}\right)^{2}
\end{gathered}
$$

$T_{\lambda}$ is the overall spectral transmission through the oil and the two windows, $\mathrm{r}_{\mathrm{aw}}$ is the reflectance at the airwindow interface, $\mathbf{r}_{\mathrm{mw}}$ is the reflectance at the mediawindow interface (in this case the media is silicone oil), $\tau_{\mathrm{w}}$ is the internal spectral transmission of the windows and $d$ is the thickness of the media.

For the temperature range ( 300 to $400 \mathrm{~K}$ ) where the silicone oils can be used, $\mathrm{e}_{\lambda \mathrm{b}}$ is negligible for $\lambda<2.5 \mu \mathrm{m}$ and also for $\lambda>70 \mu \mathrm{m}$. Because of this $\varepsilon$ was calculated from $\alpha_{\lambda}$ for the wavelength region $2.5<\lambda<70 \mu \mathrm{m}$. The extinction coefficient is plotted as a function of wavelength in Fig. 6. The hemispherical emittance was then calculated using Eqs. (1) to (4) for various temperatures and sheet thicknesses. The extinction coefficient has a maximum around 9 to $10 \mu \mathrm{m}$. For 300 to $400 \mathrm{~K}$, the black body hemispherical emissive power is a maximum at 8 to $10 \mu \mathrm{m}$. Since the extinction coefficient is a maximum in this wavelength region, the total hemispherical emittance will be large for the 300 to $400 \mathrm{~K}$ temperature region.

\section{Experimental Sheet Emittance}

A schematic of the test facility that was used is shown in Fig. 5. It consists of a $30 \mathrm{~cm}$ inner diameter stainless steel pipe $3.5 \mathrm{~m}$ long. The axis of the pipe is aligned with the gravity field. Vacuum conditions exist within the pipe with the pressure about 0.02 to 0.04 torr. At these conditions, aerodynamic drag on the sheet flow, as well as heat transfer due to conduction and convection, is negligible. Dow Corning 705 silicone oil is pumped up to a plenum above the slit. Within the plenum, vibrations and temperature fluctuations are damped out. The design of the slit plate is shown in Fig. 6. The fluid temperature was maintained at $373 \mathrm{~K}$, while the sink temperature was maintained with a coolant at $293 \mathrm{~K}$. Four different slit plate sizes were tested:
$100 \mu \mathrm{m} \times 12.5 \mathrm{~cm}$

$150 \mu \mathrm{m} \times 23.5 \mathrm{~cm}$

$200 \mu \mathrm{m} \times 23.5 \mathrm{~cm}$

$300 \mu \mathrm{m} \times 18.75 \mathrm{~cm}$

With these conditions, the temperature drop is very small, around $0.3 \mathrm{~K}$. For this reason, carefully calibrated ultrastable thermistors were used to measure $T_{1}$ and $T_{2}$. The thermistors are responsive to $0.01 \mathrm{~K}$ temperature changes. The upper thermistor was located directly above the slit in the plenum. The lower thermistor was located on an actuator probe which swung around horizontally and travelled vertically to position the thermistor at the coalescence point. The sink temperature does not need the accuracy that the temperature drop needs; thus, to measure the sink temperature, thermocouples were positioned on the wall of the vessel and their readings were averaged to a single sink temperature. To measure the volumetric flow rate, $Q$, the pressure drop across a calibrated orifice in the oil supply line was measured. $Q$ is calculated according to the equation

$$
\mathrm{Q}=\sqrt{\gamma \Delta \mathrm{p}}
$$

The orifice has been calibrated with Dow Corning 705 silicone oil at a temperature of $358 \mathrm{~K}$ for which $\gamma=2.92 \mathrm{~cm}^{6} / \mathrm{s}^{2} \mathrm{~Pa}$. The density and specific heat of the oil is also needed to calculate the emittance. Best fit equations were made using data from Dow Corning (Ref. 9). These equations are,

$$
\begin{gathered}
\rho=\left[1569-(1.625 \mathrm{~T})^{-1}\right] \mathrm{kg} / \mathrm{m}^{3} \\
C_{p}=\left[-9017.3+69.888 \mathrm{~T}-.15274 \mathrm{~T}^{2}\right. \\
\left.+1.1157 \times 10^{-4} \mathrm{~T}^{3}\right] \mathrm{J} / \mathrm{kg} \mathrm{K}
\end{gathered}
$$

There are two ways to determine the length of the sheet. In Ref. 5, it was shown that in the case where gravity can be neglected,

$$
\frac{L}{W}=\sqrt{\frac{W e}{8}}
$$

where We is the Weber number, the ratio of the dynamic pressure to the surface tension pressure,

$$
\mathrm{We}=\frac{\rho \mathrm{w}_{0}^{2} \tau_{0}}{\sigma}
$$


where $w_{0}$ is the velocity of the oil along the length of the sheet. It can be found by dividing the volumetric flow rate by the initial width and thickness. The initial thickness is $\tau_{\mathrm{o}}$ and $\sigma$ is the surface tension. A best fit equation of the surface tension was made from Dow Corning data and is expressed as,

$$
\sigma=[.08614-1.5379 \times 10 \mathrm{~T}] \mathrm{N} / \mathrm{m}
$$

The length can also be measured directly. The actuator probe that the lower thermistor is located on records the vertical position of the coalescence point.

Measuring the small temperature drop proved to be the most difficult part of the experiment. Although the lower thermistor was located on an actuator probe and had some range of motion, it was difficult to position it in the flow. Furthermore, at the coalescence point where the thermistor was located, the flow was often quite erratic. Fortunately, it was evident when the thermistor was no longer immersed in the flow because the temperature drop would increase considerably. This large increase was due to the lower thermistor radiating to the cold wall of the containing vessel instead of measuring the temperature of the oil. If the experiment were to be continued, an improved design for the measurement of the lower temperature would be implemented such as a cup with a hole in the bottom that collects the oil, with the thermistor located beneath the hole. Thus, the thermistor would always be in the flow. It was also a concern that temperature fluctuations upstream of the slit plate might cause error.

An experimental investigation to measure the typical fluctuations was also carried out. The thermistors response time is 1.5 seconds, thus, only the temperature fluctuations with a period greater than 1.5 seconds could be analyzed. Experiments were conducted where $T_{1}$ was measured at 1.5 second intervals. The average temperature change in this interval was found to be $0.031 \mathrm{~K}$ and the largest temperature change was found to be $0.054 \mathrm{~K}$. Fluctuations of $0.05 \mathrm{~K}$ or greater occurred 17 percent of the time. $0.05 \mathrm{~K}$ is large for our purposes, however, if the period of the fluctuations is much greater than the flow time (the time it takes a particle to tranverse the sheet or $L / w_{0}$ ), then the temperature fluctuation's effect on $\Delta \mathrm{T}$ will not be significant. The flow time was measured and found to be $1.54 \mathrm{msec}$. Since the fluctuations within the system are most likely generated from the heaters cycling on and off, the fluctuations most likely have periods much greater than $1.54 \mathrm{msec}$. Thus, it was assumed that temperature fluctuations will not affect the temperature drop due to radiation.
The resulting experimental emittance using Eq. (13) along with theoretical emittance is shown in Fig. 9. The emittance of the oil in the 300 to $400 \mathrm{~K}$ region proved to be quite high. The experimental emittance of the sheet is between 0.74 and 0.85 , depending on the sheet thickness and oil temperature. The emittance calculated from the transmittance data agreed closely with the experimental values. At T $=373 \mathrm{~K}$ there was a difference of 0.02 in the emittance measured for the $100 \mu \mathrm{m}$ sheet, a difference of 0.01 in the emittance measured for the $150 \mu \mathrm{m}$ and $200 \mu \mathrm{m}$ sheet, and a difference of 0.015 in the emittance found for the $300 \mu \mathrm{m}$ sheet. The experimental values were slightly less than the theoretical values for all sheet thicknesses. As shown in Fig. 9, the emittance increases with an increase in temperature and an increase in sheet thickness. As the temperature increases the maximum black body hemispherical spectral emissive power moves to shorter wavelengths. The spectral emittance does not have a maximum at these shorter wavelengths, thus although Fig. 9 does not show this effect, the overall hemispherical emittance will eventually begin to decrease as the temperature increases. In the case of $\varepsilon$ dependence on sheet thickness, $\tau, \varepsilon$ approaches an asymptote as $\tau \rightarrow \infty$.

\section{Conclusion}

The emittance of the thin liquid sheet in Fig. 1 was determined by two methods. The first method was to calculate it from transmittance data. The second method used the measured temperature drop across the sheet to determine emittance. For purposes of computing the emittance from the temperature drop, $T_{1}-T_{2}$, the sheet was treated as a constant temperature device. It was shown that no significant error in the emittance results from this approximation.

From the analysis and results, several points can be made. It is evident that the liquid sheet functions well as a radiator. The experimental emittance of the sheet is between 0.74 and 0.85 , depending on the sheet thickness and oil temperature. A large emittance is needed for a space radiator, making the liquid sheet an ideal choice. There was also close agreement in the emittance value between the theoretical and experimental method. A concern in the beginning of the experiment was that measuring the small temperature drop would prove too difficult. Getting a very accurate measurement was necessary and temperature fluctuations in the oil could easily cause an incorrect measurement. By using thermistors with accuracies of $0.01 \mathrm{~K}$, the measurement was sufficiently accurate. To eliminate temperature (and velocity) fluctuations the oil flows into a large plenum before passing through 
the slit. The plenum sufficiently dampens any fluctuations. An analysis of the fluctuations of the oil showed the fluctuations to be negligible or well over an order of magnitude less than the temperature drop due to radiation.

The large emittances $(\varepsilon>0.8)$ indicate that a liquid sheet makes an excellent low mass space radiator. Before an actual liquid sheet radiator can be fabricated, however a collection method for the flow must be designed. Since the flow coalesces to a point this should simplify the collection process.

\section{References}

1. Mattick, A.T. and Hertzberg, A., "Liquid Droplet Radiators for Heat Rejection in Space,'J Joumal of Energy, Vol. 5, No. 6, Nov-Dec. 1981, pp. 387-393.

2. Teagan, W.P. and Fitzgerald, K. "Preliminary Evaluation of a Liquid Belt Radiator for Space Applications," NASA CR-174807, 1984.

3. Chubb, D.L. and White K.A. III, "Liquid Sheet Radiator," AIAA 22nd Thermophysics CP-87-1525. (Also NASA TM-89841 (1987)).

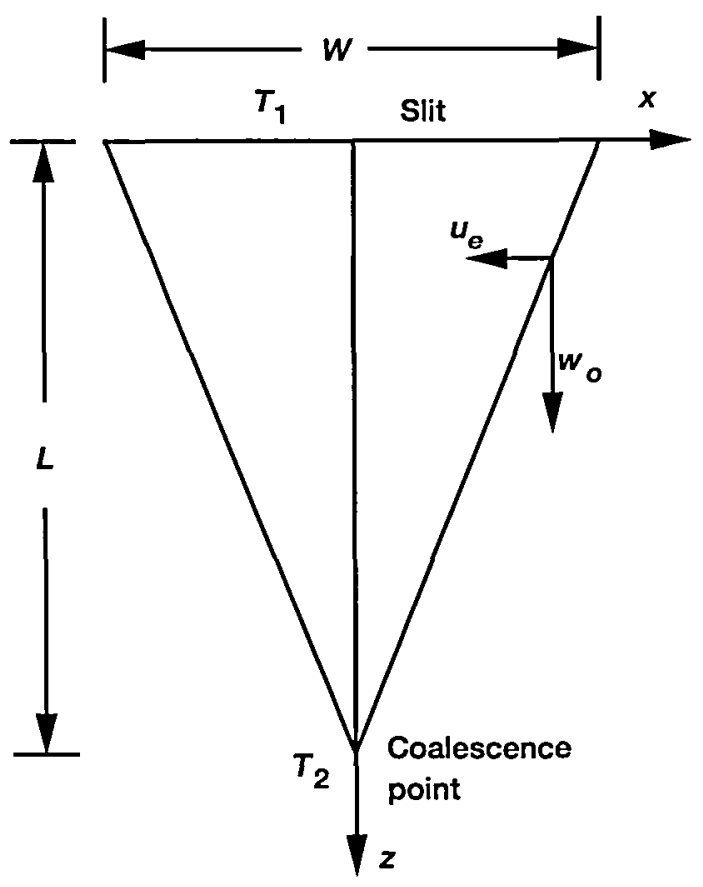

Figure 1.-Schematic of sheet
4. Siegel R. \& Howell, J.R., Thermal Radiation Heat Transfer, second edition. Hemisphere Publishing Corp., Washington, DC, 1981, pp. 52.

5. Chubb, D.L., Calfo, F.D., McConley, M.W., McMaster, M.S., and Afijeh, A.A. "The Geometry of Thin Liquid Sheet Flows." AIAA Journal, Vol. 32, No. 6, 1993, pp.1325-1328.

6. Chubb, D.L., Calfo, F.D., and McMaster, M.S. Current Status of Liquid Sheet Radiator Research." NASA TM-105764. 1992.

7. Chubb, D.L., and Calfo, F.D. "Scaling Results for the Liquid Sheet Radiator (LSR)."NASA TM-102100. 1989.

8. Thermometrics, 808 U.S. Highway \#1, Edison, New Jersey, 08817-4695, (908) 287-2870,

9. Dow Corning, South Saginaw Road, Midland, MI, 48686, (517) 496-6000.

10. Stephenson, G. and Radmore P.M. Advanced Mathematical Methods for Engineering and Science Students. Cambridge University Press. Cambridge, 1990, pp. 195199.

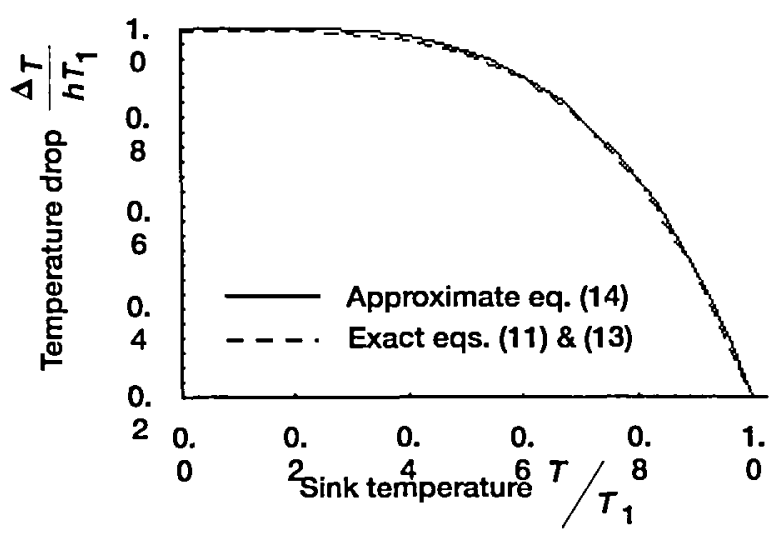

Figure 2.-Temperature drop dependence on sink temperature, $\boldsymbol{h}=\mathbf{0 . 0 0 4}$. 


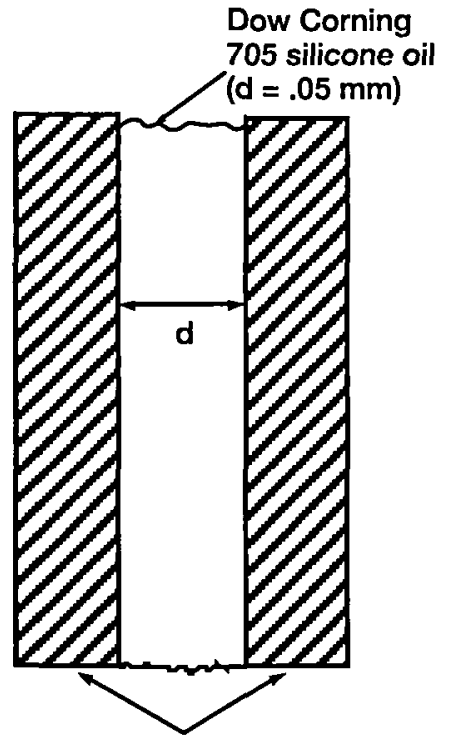

$\mathrm{KBr}$ windows (thickness $=1.0 \mathrm{~mm}$ )

Figure 3.-Schematic of oil and window configuration for transmittance measurement.

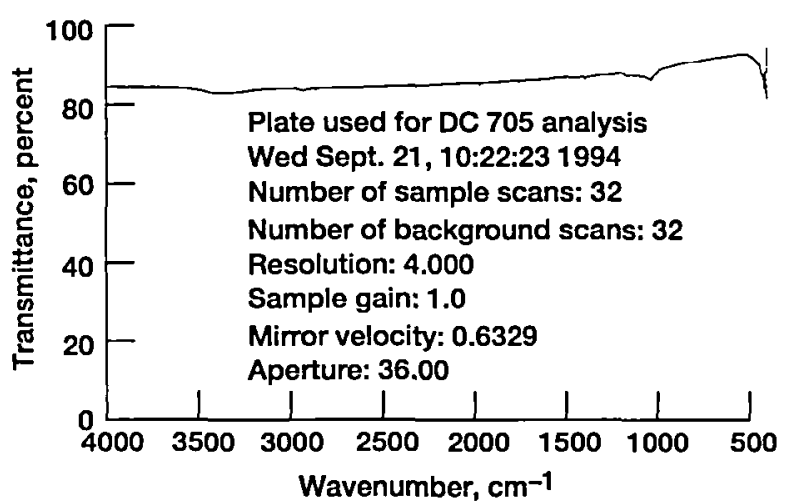

Figure 5.-Transmittance of potassium bromide window.

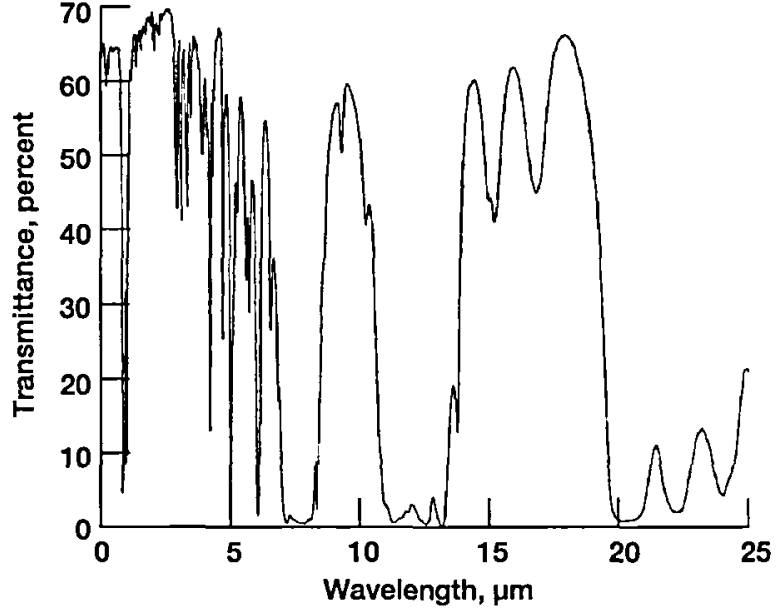

Figure 4.-Transmittance of Dow Coming 705 Silicone oil.

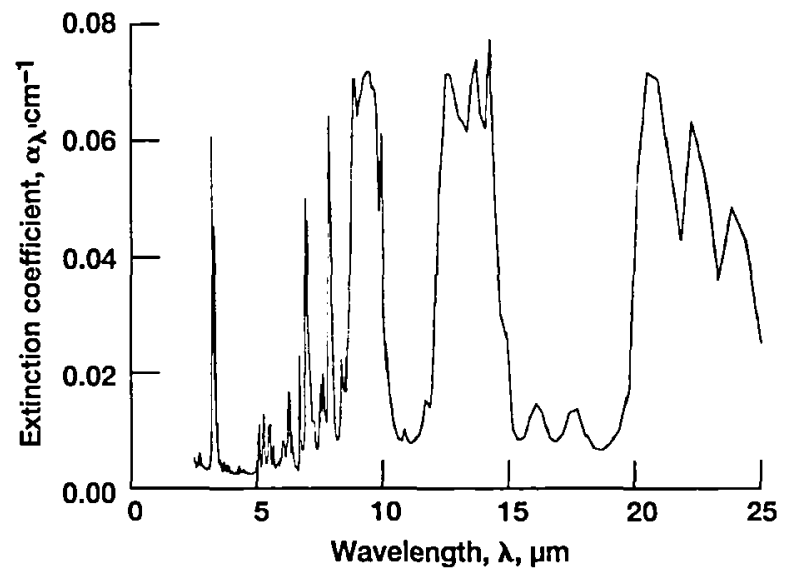

Figure 6.-Extinction coefficient for Dow Coming 705 silicone oil. 


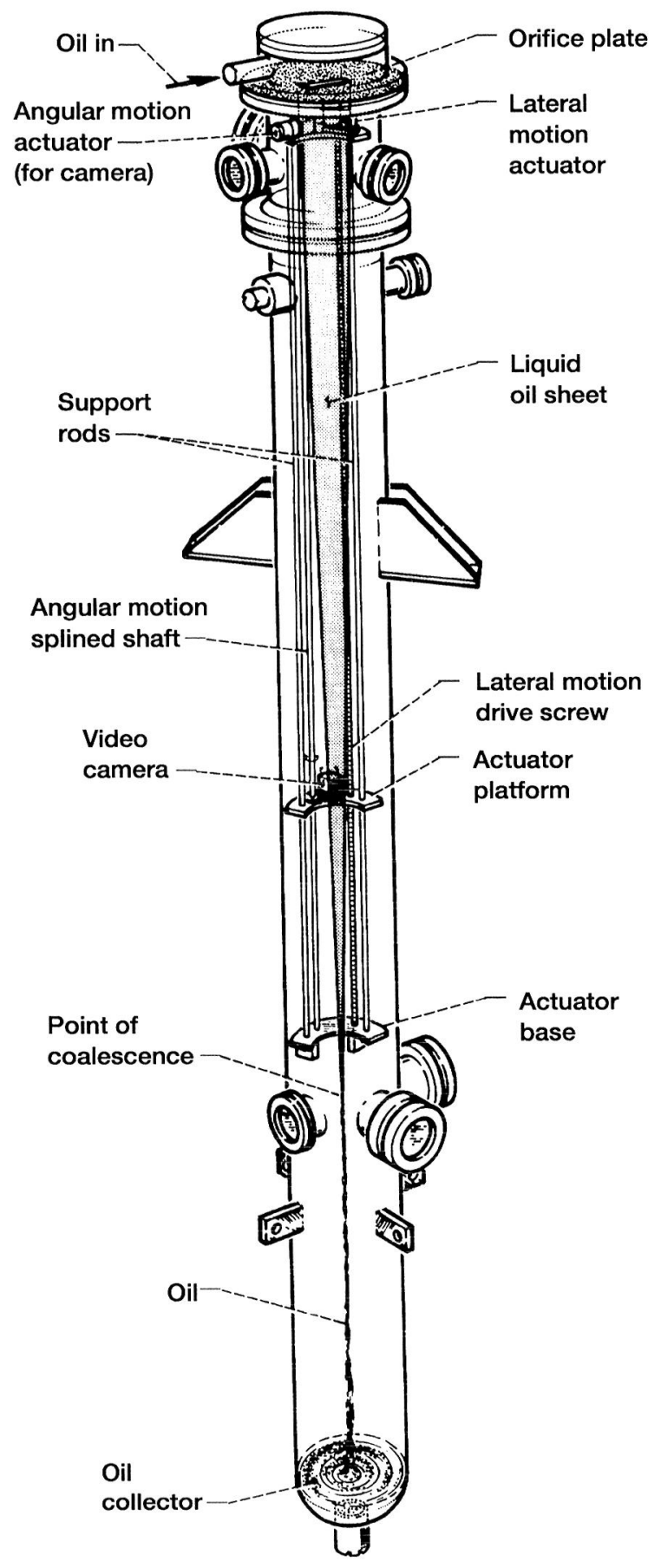

Figure 7.-Schematic of test facility. Liquid sheet radiator experiment.

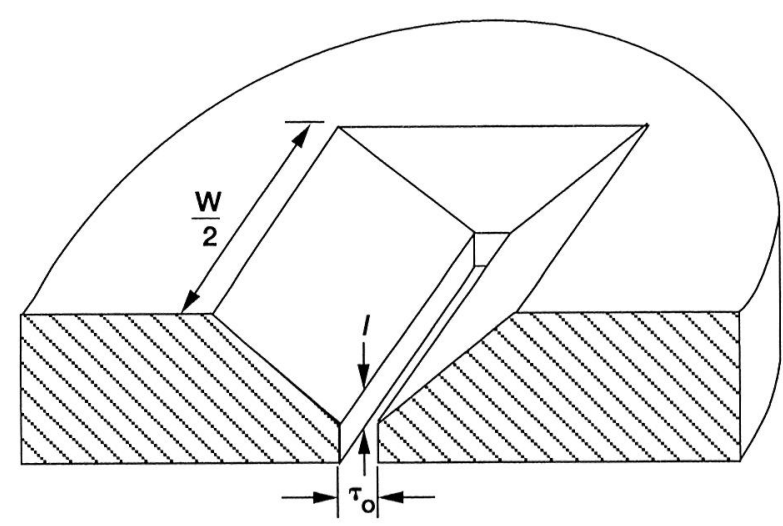

Figure 8.-Slit plate design.

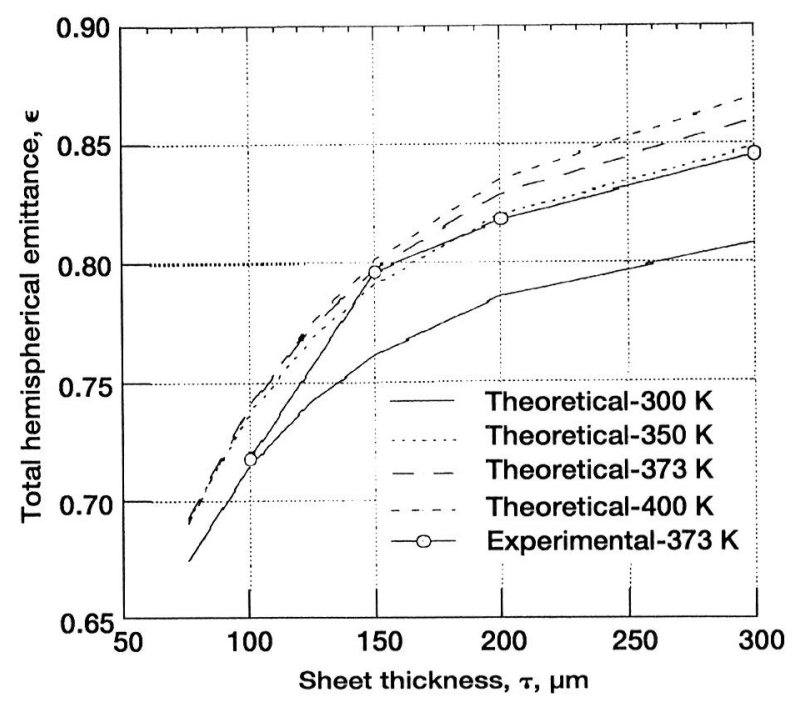

Figure 9.-Comparison of theoretical and experimental total hemispherical emittance for Dow 705 oil. 


\section{Appendix A-Extinction Coefficient Derivation}

At each interface in Fig. A-1, equations can be written for the energy flux (the incident radiation, $q_{i}$, and the outgoing radiation, $q_{o}$, for each side of the interface.) The primed variables refer to the radiation on the right side of the interfaces of Fig. A-1 and the unprimed variables refer to the radiation on the left side of the interfaces of Fig. A-1. The general form of the four equations for interfaces $b=1,2,3$ and 4 is

$$
\begin{aligned}
& q_{o b}^{\prime}=r_{b} q_{i b}^{\prime}+\left(1-r_{b}\right) q_{i b} \\
& q_{o b}=r_{b} q_{i b}+\left(1-r_{b}\right) q_{i b}^{\prime} \\
& \mathrm{q}_{\mathrm{ib}}=\tau_{\mathrm{b}-1} \mathrm{q}_{\mathrm{ob}-1}^{\prime} \quad\left(\text { except } \mathrm{q}_{\mathrm{il}}=1\right) \\
& \mathrm{q}_{\mathrm{ib}}^{\prime}=\tau_{\mathrm{b}} \mathrm{q}_{\mathrm{ob}+1} \quad\left(\text { except } \mathrm{q}_{\mathrm{i} 4}^{\prime}=0\right) \quad(\mathrm{A}-4)
\end{aligned}
$$

where $q$ is the energy flux, or the energy per unit area per unit time, $\tau_{1}$ is the transmission of window $I, \tau_{2}$ is the transmission of the media, $\tau_{3}$ is the transmission of window II, $r_{1}$ and $r_{4}$ are the reflectances at the air-window interfaces, and $r_{2}$ and $r_{3}$ are the reflectances at the mediawindow interfaces.

These four flux equations are used to write energy balances for each of the four interfaces. The sixteen resulting equations can be written as a system of equations. $\mathrm{q}_{04}^{\prime}=\mathrm{T}$ where $\mathrm{T}$ is the total transmission through the media to be tested and through the plates (windows) in which the media is contained. Algebraic manipulations show that,

$$
q_{o 4}=\frac{r_{4}}{1-r_{4}} q_{o 4}^{\prime}=\frac{r_{4}}{1-r_{4}} T
$$

The system of equations is then solved for $\mathrm{q}_{\mathrm{o} 4}$ and yields,

$$
q_{04}=\frac{r_{4} \tau_{1} \tau_{3} \tau_{2}\left(1-r_{1}\right)\left(1-r_{2}\right)\left(1-r_{3}\right)}{\left(1-r_{4} r_{2} \tau_{1}^{2}\right)\left(1-r_{3} r_{4} \tau_{3}^{2}\right)-\tau_{2}^{2}\left(r_{2}+r_{1} \tau_{1}^{2}\left[1-2 r_{2}\right]\right)\left(\left(_{3}+r_{4} \tau_{3}^{2}\left[1-2 r_{3}\right]\right)\right.}
$$

Since,

$$
\mathrm{q}_{\mathrm{o} 4}=\frac{\mathrm{r}_{4}}{1-\mathrm{r}_{4}} \mathrm{~T}
$$

the transmission is solved for using Eqs. (A-6) and (A-7). This yields,

$$
T=\frac{\tau_{1} \tau_{3} \tau_{2}\left(1-r_{1}\right)\left(1-r_{2}\right)\left(1-r_{3}\right)\left(1-r_{4}\right)}{\left(1-r_{1} r_{2} \tau_{1}^{2}\right)\left(1-r_{3} r_{4} \tau_{3}^{2}\right)-\tau_{2}^{2}\left(r_{2}+r_{1} \tau_{1}^{2}\left[1-2 r_{2}\right]\right)\left(r_{3}+r_{4} \tau_{3}^{2}\left[1-2 r_{3}\right]\right)}
$$

Because $r_{1}=r_{4}, r_{2}=r_{3}$ and $\tau_{1}=\tau_{3}$, Eq. (A-8) can be simplified. If $r_{1}=r_{4}=r_{a w}$ (reflectance at air-window interface), $r_{2}=r_{3}=r_{m w}$ (reflectance at media-window interface), and $\tau_{1}=\tau_{3}=\tau_{w}$ (internal transmission of window), then

$$
T=\frac{\tau \tau_{w}\left(1-r_{a w}\right)^{2}\left(1-r_{m w}\right)^{2}}{\left(1-r_{a w} r_{m w} \tau_{w}^{2}\right)^{2}-\tau^{2}\left(r_{m w}+r_{a w} \tau_{w}^{2}\left[1-2 r_{m w}\right]\right)^{2}}
$$

where $\tau_{2}$ has been replaced by $\tau$ (transmission of media) in Eq. (A-8). Equation (A-9) is a quadratic equation for $t$ as a function of $T, r_{m w}, r_{a w}$ and $\tau_{w}$,

$$
\begin{array}{r}
\tau^{2} T\left(r_{m w}+r_{a w} \tau_{w}^{2}\left[1-2 r_{m w}\right]\right)^{2}+\tau \tau_{w}^{2}\left(1-r_{a w}\right)^{2}\left(1-r_{m w}\right)^{2} \\
-T\left(1-r_{a w} r_{m w} \tau_{w}^{2}\right)^{2}=0 \quad(A-10)
\end{array}
$$

Thus,

$$
\begin{gathered}
a=T\left(r_{m w}+r_{a w} \tau_{w}^{2}\left[1-2 r_{m w}\right]\right)^{2} \\
b=\tau_{w}^{2}\left(1-r_{a w}\right)^{2}\left(1-r_{m w}\right)^{2}
\end{gathered}
$$

$$
\begin{gathered}
c=-T\left(1-r_{a w} r_{m w} \tau_{w}^{2}\right)^{2} \\
\tau=\frac{-b \pm \sqrt{b^{2}-4 a c}}{2 a}
\end{gathered}
$$

Since, $\tau_{\lambda}=\mathrm{e}^{-\alpha \mathrm{d}}$, then the extinction coefficient can be written

$$
\alpha_{\lambda}=\frac{-\ln \left\{\frac{-b \pm \sqrt{b^{2}-4 a c}}{2 a}\right\}}{d}
$$


To solve for the extinction coefficient, the transmission of the window, $\tau_{\mathrm{w}}$, must also be calculated. It can be calculated using Eq. (A-8) illustrated above except in this case there are only two interfaces and the window is the new "media".

It can be seen that, $r_{1}=r_{4}=0, r_{2}=r_{3}=$ reflectance at airmedia interface, $\tau_{1}=\tau_{3}=1$ and $\tau=$ transmission of window. The equation for the transmission of the window becomes,

$$
T_{w}=\frac{\tau\left(1-r_{2}\right)\left(1-r_{3}\right)}{1-\tau^{2} r_{2} r_{3}}
$$

Therefore, since $r_{2}=r_{3}=r_{a w}$,

$$
\tau^{2} T_{w} r_{a w}^{2}+\tau\left(1-r_{a w}\right)^{2}-T_{w}=0
$$

and

$$
\begin{gathered}
a=T_{w} r_{a w}^{2}, \\
b=\left(1-r_{a w}\right)^{2}
\end{gathered}
$$

and

$$
\mathrm{c}=-\mathrm{T}_{\mathrm{w}} .
$$

The internal transmission of the window is written then as

$$
\tau_{w}=\frac{-\left(1-r_{a w}\right)^{2} \pm \sqrt{\left(1-r_{a w}\right)^{4}+4 T_{w}^{2} r_{a w}^{2}}}{2 T_{w} r_{a w}^{2}} \quad(A-21)
$$

The internal transmission of the window as a function of wavelength is used in Eqs. (A-14) and (A-15) and the extinction coefficient of the oil is then calculated and used to find the spectral emittance.

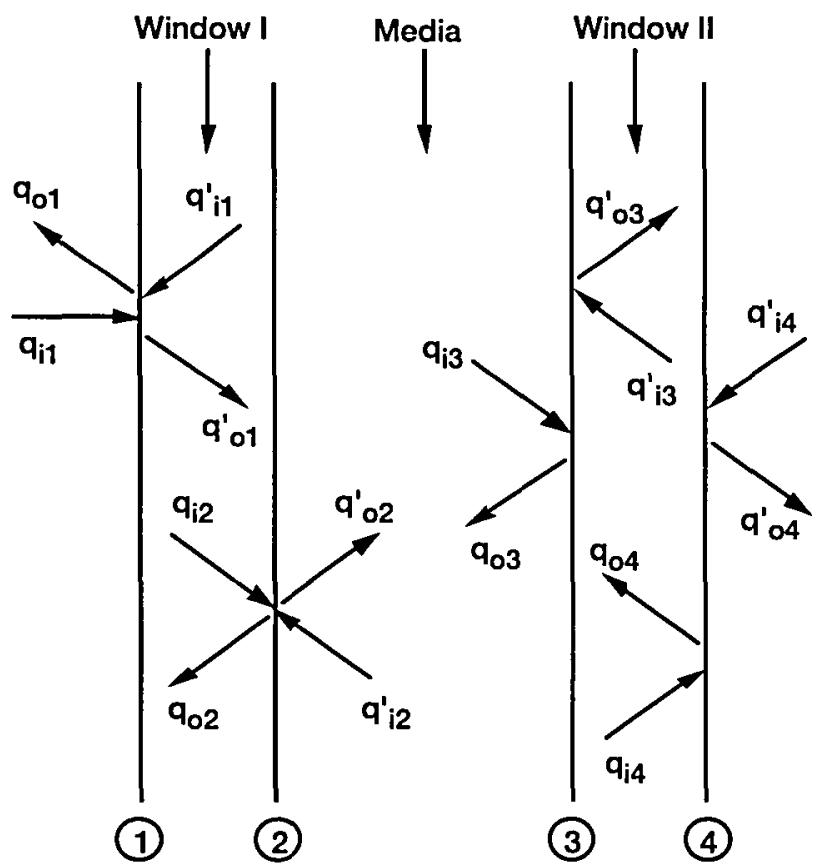

Figure A-1.-Energy flux of absorbing media between transmitting windows. 


\section{Appendix B-Limit Calculations for Sheet Temperature Drop}

In the limit of low background temperature $\left(\mathrm{T}_{\infty} \rightarrow 0\right)$, the energy equation no longer has the solution (7). Instead, we must solve the modified energy equation:

$$
\frac{\mathrm{dT}}{\mathrm{T}^{4}}=-2 \mathrm{hT}_{1}^{-3} \mathrm{~d} \overline{\mathrm{z}}
$$

which has the explicit solution:

$$
\frac{\mathrm{T}}{\mathrm{T}_{1}}=-(6 \mathrm{~h} \overline{\mathrm{z}}+1)^{-1 / 3}
$$

The solution Eq. (B-2) can be substituted directly into the power balance Eq. (11). This yields:

$$
\begin{aligned}
\lim _{\mathrm{T}_{\infty \rightarrow 0}} \frac{\Delta \mathrm{T}}{\mathrm{hT}}= & 2 \int_{0}^{1}(6 \mathrm{~h} \overline{\mathrm{z}}+1)^{-4 / 3}(1-\overline{\mathrm{z}}) \mathrm{d} \overline{\mathrm{z}}=\frac{1}{18 \mathrm{~h}^{2}} \\
& \times \int_{1}^{6 \mathrm{~h}+1}\left[(6 \mathrm{~h}+1) \mathrm{u}^{-4 / 3}-\mathrm{u}^{-1 / 3}\right] \mathrm{du} \quad(\mathrm{B}-3)
\end{aligned}
$$

The integration of Eq. (B-3) is straightforward and results in

$$
\lim _{\mathrm{T}_{\infty \rightarrow 0}} \frac{\Delta \mathrm{T}}{\mathrm{hT}_{1}}=\frac{4 \mathrm{~h}+1-(6 \mathrm{~h}+1)^{2 / 3}}{4 \mathrm{~h}^{2}}
$$

Since the range of $h$ is 0.0004 to 0.004 , or $h \ll<1$, the temperature drop is found to be:

$$
\lim _{T_{\infty} \rightarrow 0} \frac{\Delta T}{h T_{1}}=\frac{4 h+1-(6 h+1)^{2 / 3}}{4 h^{2}} \approx 1
$$

The relative error in $\Delta T$ resulting from the constant temperature assumption (that is, $\Delta \mathrm{T}=\mathrm{hT}_{1}$ ) was found numerically to be proportional to $h$. In the limit:

$$
\begin{aligned}
\lim _{T_{\infty} \rightarrow 0} \frac{(\Delta T)_{\text {approx }}-(\Delta T)_{\text {exact }}}{(\Delta T)_{\text {approx }}} \\
\quad=\frac{4 h^{2}-4 h-1+(6 h+1)^{2 / 3}}{4 h^{2}}=\frac{8}{3} h
\end{aligned}
$$

As $h$ increases, this ratio decreases asymptotically to zero, so the following inequality holds:

$$
\lim _{T_{\infty} \rightarrow 0} \frac{(\Delta T)_{\text {approx }}-(\Delta T)_{\text {exact }}}{(\Delta T)_{\text {approx }}} \leq \frac{8 h}{3} \quad(B-7)
$$

While the low sink temperature limit is appropriate for space applications, typical experimental conditions may have sink temperatures relatively close to the fluid temperature (such as the room temperature, for example). It has been found numerically that the percent error due to the constant temperature approximation has a minimum at $T_{\infty}=0$ and increases slightly with increasing $T_{\infty}$. Thus it is desirable to verify that this percent error never exceeds the limit of $8 \mathrm{~h} / 3$ regardless of the sink temperature. This can be done by considering the limit $T_{\infty} \rightarrow T_{1}$.

Two new parameters, $\phi$ and $\chi$, are defined in the following way:

$\frac{T}{T_{1}}=1-\phi, \quad \frac{T_{\infty}}{T_{1}}=1-\chi, \quad$ for $\phi \rightarrow 0, \chi \rightarrow 0 \quad(B-8)$

In the constant temperature approximation, $\phi=0$ and Eq. (B-8) can be substituted into Eq. (11) to obtain:

$$
\lim _{\mathrm{T}_{\infty} \rightarrow \mathrm{T}_{1}} \frac{\Delta \mathrm{T}}{\mathrm{hT} \mathrm{T}_{1}}=1-(1-\chi)^{4} \rightarrow 4 \chi
$$

Being interested only in limits, $\chi$ is taken to be arbitrarily small and terms of higher than first order are neglected. The "exact" solution is found from the energy Eq. (12), which becomes:

$$
\frac{\mathrm{dT} / \mathrm{T}_{1}}{(1-\phi)^{4}-(1-\chi)^{4}} \rightarrow \frac{\mathrm{d} \phi}{4(\phi-\chi)}=-2 \mathrm{hd} \overline{\mathrm{z}}
$$

This equation has a closed-form solution, namely:

$$
\phi=\chi\left(1-\mathrm{e}^{-8 \mathrm{~h} \bar{z}}\right)
$$

Substituting Eqs. (B-11) into (11) and eliminating higher order terms yields:

$$
\lim _{T_{\infty} \rightarrow T_{1}} \frac{\Delta T}{h T_{1}}=2 \int_{0}^{1}\left[(1-\phi)^{4}-(1-\chi)^{4}\right][1-\bar{z}] d \bar{z} \rightarrow 2
$$

$$
\begin{gathered}
\int_{0}^{1} 4[-\phi+\chi][1-\overline{\mathrm{z}}] \mathrm{d} \overline{\mathrm{z}}=8 \chi \int_{0}^{1} \mathrm{e}^{-8 \mathrm{~h} \bar{z}}[1-\overline{\mathrm{z}}] \mathrm{d} \overline{\mathrm{z}} \\
=\frac{\chi}{8 \mathrm{~h}^{2}\left[8 \mathrm{~h}-1+\mathrm{e}^{-8 \mathrm{~h}}\right]} \quad(\mathrm{B}-12)
\end{gathered}
$$


Combining Eqs. (B-9) and (B-12), the limit on the error in making the constant temperature approximation is determined by:

$$
\lim _{\infty \rightarrow T_{1}} \frac{(\Delta \mathrm{T})_{\text {approx }}-(\Delta \mathrm{T})_{\text {exact }}}{(\Delta \mathrm{T})_{\text {approx }}}=\frac{32 \mathrm{~h}^{2}-8 \mathrm{~h}+1-\mathrm{e}^{-8 \mathrm{~h}}}{32 \mathrm{~h}^{2}}=\frac{8}{3} \mathrm{~h}
$$

As $h$ increases, this ratio also decreases asymptotically to zero, so there is an upper bound equivalent to Eq. (B-7); that is,

$$
\lim _{\infty \rightarrow T_{1}} \frac{(\Delta \mathrm{T})_{\text {approx }}-(\Delta \mathrm{T})_{\text {exact }}}{(\Delta \mathrm{T})_{\text {approx }}} \leq \frac{8 \mathrm{~h}}{3} \quad(\mathrm{~B}-14)
$$

Therefore, the results of Eqs. (B-7) and (B-14) hold for any $T_{\infty} \leq T_{1}$. 
Public reporting burden for this collection of information is estimated 10 average 1 houp per response, including the time for reviewing instructions, searching existing data sources, gathering and maintaining the data needed, and completing and reviewing the colbection of information. Send comments regarding this burden estimale or any other aspert of this collection of information, including suggestions for reducing this burden, to Washington Headquarters Services, Directorate for iniormation Operations and Reports, 1215 Jefierson Davis Highway, Suite 1204. Arlington. VA 22202-4302, and to the OHtice of Managernent and Budget, Papenwork Reduction Project (0704-0188). Washington. DC 20503.
1. AGENCY USE ONLY (Leave blank)
2. REPORT DATE
September 1995
3. REPORT TYPE AND DATES COVERED
Technical Memorandum

4. TITLE AND SUBTTILE

Theoretical and Experimental Emittance Measurements for a Thin

Liquid Sheet Flow

6. AUTHOR(S)

Amy N. Englehart, Marc W. McConley, and Donald L. Chubb

7. PERFORMING ORGANIZATION NAME(S) AND ADDRESS(ES)

National Aeronautics and Space Administration

Lewis Research Center

Cleveland, Ohio 44135-3191
WU-233-10-0D

5. FUNDING NUMBERS

8. PERFORMING ORGANIZATION REPORT NUMBER

E-9842

\section{SPONSORING/MONITORING AGENCY NAME(S) AND ADDRESS(ES)}

National Aeronautics and Space Administration

Washington, D.C. 20546-0001
10. SPONSORINGMONITORING AGENCY REPORT NUMBER

NASA TM-107026

\section{SUPPLEMENTARY NOTES}

Portions of this material were presented at the 34th Aerospace Sciences Meeting sponsored by the American Institute of Aeronautics and Astronautics, Reno, Nevada, January 15-18, 1996. Amy N. Englehart, Cleveland State University, Cleveland, Ohio 44115, Marc W. McConley, Massachusetts Institute of Technology, Cambridge, Massachusetts 02139, and Donald L. Chubb, NASA Lewis Research Center. Responsible person, Donald L. Chubb, organization code 5410, (216) 433-2242.

12a. DISTRIBUTION/AVAILABILTTY STATEMENT 12b. DISTRIBUTION CODE

Unclassified - Unlimited

Subject Category 34

This publication is available from the NASA Center for Aerospace Information, (301) 621-0390.

13. ABSTRACT (Maximum 200 words)

Surface tension forces at the edges of a thin liquid $(-200 \mu \mathrm{m})$ sheet flow result in a triangularly shaped sheet. Such a geometry is ideal for an extemal flow radiator. Since the fluid must have very low vapor pressure, Dow Corning 705 silicone oil was used and the emittance of a flowing sheet of oil was determined by two methods. The emittance was derived as a function of the temperature drop between the top of the sheet and the coalescence point of the sheet, the sink temperature, the volumetric flow and the length of the sheet. The emittance for the oil was also calculated using an extinction coefficient determined from spectral transmittance data of the oil. The oil's emittance ranges from .67 to.87 depending on the sheet thickness and sheet temperature. The emittance derived from the temperature drop was slightly less than the emittance calculated from transmittance data. An investigation of temperature fluctuation upstream of the slit plate was also done. The fluctuations were determined to be negligible, not affecting the temperature drop which was due to radiation.

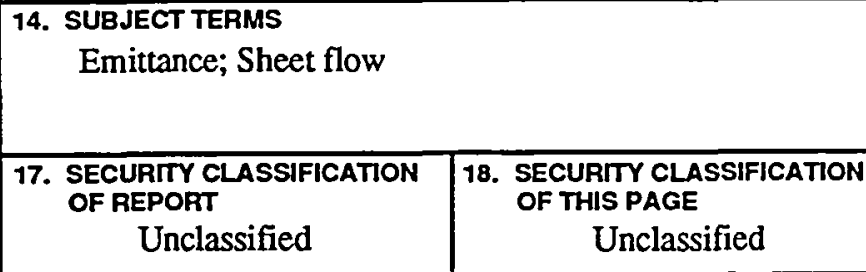

\begin{tabular}{|c|c|}
\hline & $\begin{array}{c}\text { 15. NUMBER OF PAGES } \\
14\end{array}$ \\
\hline & $\begin{array}{r}\text { 16. PRICE CODE } \\
\text { A03 }\end{array}$ \\
\hline $\begin{array}{l}\text { 19. SECUAITY CLASSIFICATION } \\
\text { OF ABSTRACT } \\
\text { Unclassified }\end{array}$ & 20. LIMITATION OF ABSTRACT \\
\hline
\end{tabular}


National Aeronautics and

Space Administration

Lewis Research Center

21000 Brookpark Rd.

Cleveland, $\mathrm{OH}$ 44135-3191

Official Business

Penalty for Private Use $\$ 300$

POSTMASTER: If Undeliverable - Do Not Return

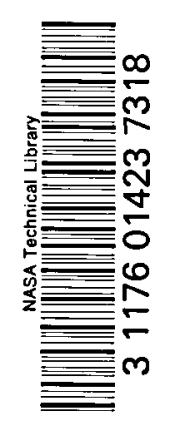

